\title{
@ळछత Porque devemos desconfiar da intuição repugnante *
}

Resumo: A Conclusão Repugnante é a afirmação, proposta por Derek Parfit (1984, p. 388), de que uma população de pelo menos 10 bilhões de pessoas vivendo vidas muito boas é, se todas as outras coisas forem iguais, pior do que uma população suficientemente maior de pessoas vivendo vidas muito ruins. Neste artigo, pretendo mostrar porque devemos desconfiar da intuição, que muitos de nós temos, de que a Conclusão Repugnante é obviamente falsa. Primeiro, seguindo por um lado Broome (2004) e por outro Gustafsson (no prelo), defendo que devemos desconfiar dessa intuição "repugnante" porque ela exige que imaginemos quantidades extraordinariamente grandes de números e, por consequência, nós as imaginamos de maneira inexata. Depois, objeto duas maneiras de se argumentar contra este ceticismo sobre a veracidade de intuições que exigem imaginarmos quantidades numéricas extraordinariamente grandes, uma proposta por Temkin (2012) e outra por Pummer (2013). Por fim, como a solidez de ambas as maneiras de argumentar depende de que sejamos capazes de decidir a verdade aparente de proposições modais que, seguindo o ceticismo modal de Inwagen (1998), não conseguimos decidir, pois afirmam a possibilidade metafísica de entes extraordinários existirem, concluo que devemos manter nossa desconfiança sobre a intuição repugnante.

O presente artigo contou com o apoio financeiro da CNPq, por meio do programa PIBIC. Expresso aqui minha gratidão pelo apoio. Também gostaria de agradecer ao Grupo de Pesquisa em Ética da Universidade Federal de Uberlândia, em especial ao meu orientador prof. Alcino Eduardo Bonella, aos meus colegas Arthur Falco e Mateus Patricio e as minhas colegas Emely Verona e Natália Amorim, pelos comentários que fizeram a uma versão prévia desse artigo. Por fim, agradeço a minha querida Ariadne, por acreditar nas minhas ambições e compreender minhas frustrações

** Graduando em Filosofia pela Universidade Federal de Uberlândia. E-mail: andre.1.1.figueredo@ufu.br. Orcid: https://orcid.org/0000-0002-1966-454X. CV: http://lattes.cnpq.br/3959666585010339. 
Palavras-chave: Ética Populacional; Conclusão Repugnante; Ceticismo; Ceticismo Modal.

\section{Why we should distrust the repugnant intuition}

Abstract: The Repugnant Conclusion is the claim, proposed by Derek Parfit (1984, p. 388), that a population of at least 10 billion people living very good lives is, if other things are equal, worse than a sufficiently large population of people living very bad lives. In this article, I aim to show why we should distrust the intuition we might have that the Repugnant Conclusion is obviously false. First, following Broome (2004) in a way and Gustfasson (forthcoming) in another, I argue that we should distrust this "repugnant" intuition because it demands that we imagine extraordinarily large quantities and, by consequence, we imagine them inexactly. Afterward, I object against two modes of arguing against this skepticism about the veracity of intuitions which demands that we imagine extraordinarily large quantities of numbers, one proposed by Temkin (2012) and the other by Pummer (2013). Finally, since the soundness of both modes depends on wether we are capable of deciding the truth of modal propositions that, following the modal skepticism of Inwagen (1998), we cannot decide, for they state that it's metaphysically possible that extraordinary beings exist, I conclude that we should maintain our distrust towards the repugant conclusion.

Keywords: Population Ethics; Repugnant Conclusion; Skepticism; Modal Skepticism.

\section{Introdução}

Um problema fulcral para a ética populacional, mais especificamente para a axiologia populacional, consiste em saber se a seguinte conclusão, proposta de forma seminal por Derek Parfit (1984, p. 388), é verdadeira ou falsa:

Conclusão Repugnante. Para qualquer população possível de pelo menos 10 bilhões de pessoas, todas com uma qualidade de vida muito alta, 
deve existir uma outra população possível bem maior cuja existência, se as outras coisas forem iguais, seria melhor, mesmo que seus habitantes tenham vidas que quase não valem a pena serem vividas

Teoricamente, essa conclusão deve ser verdadeira se aceitarmos que é verdadeira uma teoria totalista sobre como ordenar situações em função do bem-estar delas, que pode ser definida pela defesa que faz do seguinte princípio de ordenação: dadas duas situações A e B, A é melhor que B se, e somente se, o bem-estar total de A é maior que o bem-estar total de B; se A e B tiverem a mesma quantidade de bem-estar total, então A é igualmente bom a B. O Utilitarismo, por exemplo, é uma conhecida teoria moral que adota essa axiologia totalista, somando-a com uma teoria normativa consequencialista $^{1}$ - que pode ser definida pela defesa que faz da seguinte tese sobre o critério de correção de uma ação: deve-se decidir se uma ação é permissível, requerida ou proibida apenas com base no quão boas serão as consequências dessa ação.

Não é difícil entender como essa axiologia totalista implica a Conclusão Repugnante. Supondo que a população A, que tem 10 bilhões de habitantes, todos com alta qualidade de vida, tenha uma quantidade total de bem-estar $n$, então existe alguma população $\mathrm{B}$, que tem uma quantidade $h$ de

1 A princípio, toda teoria normativa que atribua relevância moral para o bem das consequências, não necessariamente exclusiva, também está apta a implicar a Conclusão Repugnante, dado que os outros fatores potencialmente relevantes (e.g. causar dano a inocentes, mentir, ferir a autonomia, etc.) são assumidamente iguais em ambas as populações, como evidenciado pela cláusula "se as outras coisas forem iguais" (if other things are equal). Pela mesma razão, não é só uma teoria "bem-estarista" (welfarist) do bem, que defende que o bem é constituído exclusivamente de bem-estar, que está sujeita a implicar essa conclusão. É suficiente, para implicá-la, que a teoria moral adote uma axiologia totalista, independentemente de quais sejam suas teorias normativa e do bem. No entanto, não é necessário que uma teoria moral adote uma axiologia totalista para que ela implique a Conclusão Repugnante, primeiro porque outras axiologias implicam conclusões tão ou até mais repugnantes que a Conclusão Repugnante, e segundo porque outras teorias axiológicas podem implicar a Coclusão Repugnante sem que seja preciso adotar alguma axiologia determinada, por meio de outras duas formas de se argumentar a favor da verdade da Conclusão Repugnante, mais convincentes do que a forma de argumentar via axiologia totalista (que se baseia na verdade de uma axiologia determinada). Para uma explicação acessível dessas outras formas por meio das quais uma teoria axiológica pode implicar a Conclusão Repugnante, conferir Cowie, 2019, cap. 2 
habitantes, todos com uma qualidade de vida $v$ tão baixa a ponto de quase não valer a pena viver, que é grande o suficiente para que sua quantidade total de bem-estar $h v$ seja maior que a quantidade $n$ da população $\mathrm{A}^{2}$; logo, a população B é melhor que a população A. No diagrama abaixo, em que a largura dos retângulos representa o bem-estar da população e a altura a sua quantidade de habitantes, podemos visualizar essa implicação de se ordenar populações levando em conta somente suas somas totais de bem-estar. Parece que apesar dos habitantes de B terem, individualmente, um bem-estar muito menor do que os habitantes de $\mathrm{A}$, como podemos ver pela altura dos dois retângulos, ainda assim, um totalista diria que pela população $\mathrm{B}$ ter mais bem-estar total do que A, como evidenciado pelas áreas dos retângulos, então B é melhor do que A.

\section{Bem-estar}

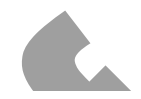
muito alto

Bem-estar muito baixo e população bem maior que em A

A

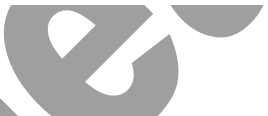

$\mathrm{Z}$

Intuitivamente, no entanto, essa conclusão parece bastante contraintuitiva, a ponto de ter sido considerada como "repugnante" por Parfit, i.e., como "obviamente falsa" (TÄNNSJÖ, 2002). De fato, para muitos de nós A é, prima facie, claramente melhor do que $\mathrm{B}$, ao contrário do que afirma a Conclusão Repugnante. Diante desta inconsistência entre a

${ }^{2}$ Assumindo que não existe um limite na quantidade de habitantes de uma população possível e que a escala de bem-estar usada seja similar a dos números reais (ARRHENIUS, p. 49-50; GREAVES, 2017, p. 3) 
teoria axiológica totalista, que implica a Conclusão Repugnante, e a nossa intuição de que essa conclusão é obviamente falsa, a questão que me interessa investigar é a seguinte: devemos — i.e., estamos justificados a confiar nessa intuição "repugnante" que nos impele a acreditar que a conclusão é obviamente falsa? Temos ao menos uma razão para crer que não devemos ${ }^{4}$ : a de que nós não podemos confiar nessa intuição porque não podemos confiar em nossas intuições quando elas exigem que imaginemos uma quantidade muito grande de números (NG, 1989; TÄNNSJÖ, 2002; BROOME, 2004; HUEMER, 2008; GUSTAFSSON, no prelo).

Neste artigo, objetarei a um argumento que defende que nós não devemos desconfiar dessa intuição repugnante por conta dessa razão, já que essa intuição não exige que imaginemos uma quantidade muito grande de números e, portanto, essa razão não se aplica à intuição repugnante. Esse argumento é proposto de duas maneiras diferentes, uma por Larry Temkin (2012) e outra por Theron Pummer (2013). Antes de expor o argumento a partir dessas duas maneiras e minhas objeções a ele (nas seções 3 e 4, respectivamente), esclareço o porquê de eu acreditar que devemos desconfiar da intuição repugnante (na seção 2). Por fim (na seção 5), concluo que nós devemos nos manter céticos quanto à intuição repugnante, pois essas duas maneiras de se argumentar a favor de não nos mantermos céticos, a favor de confiarmos nessa intuição, só são sólidas se uma proposição modal, que afirma a possibilidade metafísica de entes extraordinários existirem, for aparentemente verdadeira, porém, seguindo o ceticismo modal de Inwagen (1998), nós não conseguimos decidir, de maneira a priori, se ela é aparentemente verdadeira, posto que essa

${ }^{3}$ Não devemos interpretar esse nome, "intuição repugnante", como se ele significasse que a intuição é obviamente falsa, i.e., como se a própria intuição fosse repugnante. $\mathrm{O}$ nome apenas significa que essa intuição é a intuição que muitos de nós temos diante da Conclusão Repugnante, que é uma intuição da repugnância dessa conclusão, i.e., da sua óbvia falsidade.

${ }^{4}$ Para um compilado de razões para não confiarmos nessa intuição, e outras maneiras de lidar com a Conclusão Repugnante, ver Arrhenius et al, 2006; Zuber et al, 2021. 
proposição modal pressupõe a existência de entes extraordinários que nós não conseguimos imaginar como poderiam vir a existir.

\section{A razão da desconfiança}

Como já indicado na Introdução, a razão do meu ceticismo é que essa intuição exige que imaginemos uma quantidade muito grande de números. Por sua vez, essa razão pode ser justificada por pelo menos cinco razões: a de que 1) depois de uma certa quantidade muito grande de números, nós imaginamos todas as quantidades de números como se fossem praticamente iguais, o que significa que nós não compreendemos a devida grandeza dessas quantidades (HUEMER, 2008, p. 907-908); a de que 2) nós atribuímos uma importância inadequada a números grandes porque não conseguimos nos identificar de maneira adequada, empaticamente, com um número grande de pessoas (TÄNNSJÖ, 2002, p. 344); a de que 3) nós subestimamos a grandeza de uma quantidade grande que é composta por várias quantidades pequenas (HUEMER, 2008, p. 909-910); a de que 4) uma quantidade muito grande de números é extraordinária, e para que uma intuição seja confiável, ela deve ser formada e aperfeiçoada por interações ordinárias entre o sujeito que intui e os objetos da intuição (BROOME, 2004, p. 57); a de que 5) nós imaginamos uma quantidade muito grande de números de maneira inexata, com uma margem de erro que pode nos levar a acreditar que o produto dessa quantidade muito grande, por outra quantidade, é bem menor do que ele realmente seria se tivéssemos imaginado a quantidade grande de maneira exata (GUSTAFSSON, no prelo).

A razão que defendo ser a mais adequada, para justificar a crença cética de que devemos desconfiar de intuições que exigem imaginar uma quantidade muito grande de números, é uma junção da quarta com a quinta: a intuição repugnante não é confiável porque exige que imaginemos uma quantidade extraordinariamente grande de pessoas e, consequentemente, nós a imaginamos de maneira inexata. Logo, é por essas intuições serem inexatas que nós estamos justificados a desconfiar delas (pela quinta razão), 
e o que explica elas serem inexatas é que elas exigem que imaginemos coisas extraordinárias (pela quarta razão).

Entretanto, parece que essa inexatidão de nossas intuições, que ocorre quando imaginamos uma quantidade extraordinária de números, nem sempre nos leva a compararmos equivocadamente diferentes alternativas de populações. E este é um dos motivos pelo qual acredito que essa razão, que consiste na junção entre a quarta com a quinta, é a mais adequada para justificar que desconfiemos da intuição repugnante, pois diferente dela, a primeira e a segunda razão não conseguem explicar como em alguns casos nós achamos que podemos confiar em certas comparações, que exigem nossas intuições sobre quantidades extraordinariamente grandes, se nós achamos que não podemos confiar nessas intuições.

Por exemplo, de acordo com Gustafsson (Idem), a primeira razão não consegue explicar porque nós acreditamos que existem comparações em que, mesmo se nós não compreendermos a devida grandeza de uma população $\mathrm{C}$, porque ela tem uma quantidade de pessoas muito grande, assumidamente acima do nível em que imaginamos todas as quantidades muito grandes como se fossem praticamente iguais, e nós também não compreendermos a devida grandeza de outra população $\mathrm{D}$, que tem uma quantidade de habitantes bem maior que a da população $\mathrm{C}$, ainda assim nós conseguimos considerar intuitivamente a diferença entre suas quantidades para julgar qual população é melhor — desde que a população $\mathrm{D}$ tenha um nível de bem-estar apenas um pouco menor que o da população $\mathrm{C}$ - mesmo assumindo que nós imaginamos as quantidades de habitantes, das populações C e D, como se fossem praticamente iguais. Para ilustrar esta comparação entre $\mathrm{C}$ e $\mathrm{D}$, segue abaixo o diagrama: 


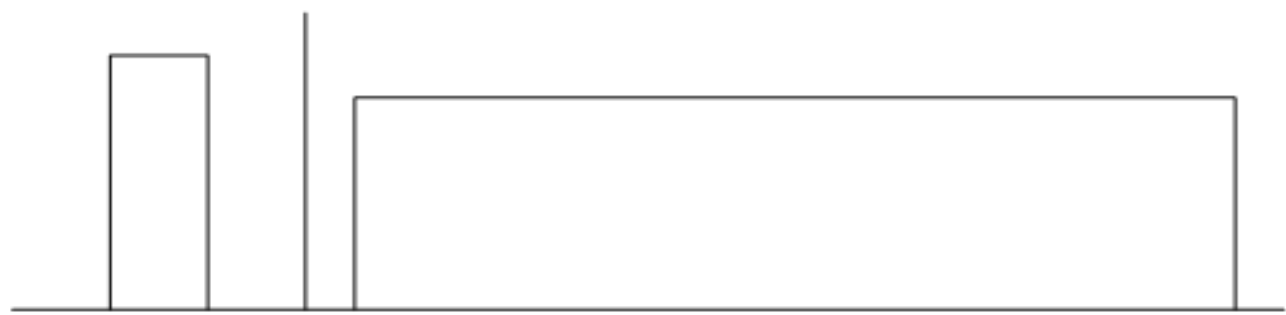

$C$

$\mathrm{D}$

Diagrama 2

Se nós imaginamos a quantidade de pessoas em $\mathrm{C}$ e a quantidade de pessoas em D como se fossem iguais, então como temos tanta confiança na crença de que $\mathrm{D}$ é melhor do que $\mathrm{C}$, em vez de $\mathrm{C}$ ser melhor que $\mathrm{D}$, dado que $\mathrm{C}$ tem o maior nível de bem-estar? Parece que conseguimos fazer essa comparação, imaginando a diferença quantitativa entre o tamanho das populações, sem nos equivocar: $\mathrm{D}$ deve ser melhor do que $\mathrm{C}$, e não o contrário. A quinta razão, proposta por Gustafsson (Idem), consegue explicar o porquê de podermos confiar nessa comparação: porque apesar de imaginarmos essas quantidades muito grandes de maneira inexata, esta inexatidão não nos leva a compararmos equivocadamente as populações $\mathrm{C} e$ $\mathrm{D}$, dado que a diferença entre seus níveis de bem-estar é suficientemente pequena; teríamos que imaginar muito errado a quantidade de pessoas de $\mathrm{D}$, superestimando muito seu tamanho, para que $\mathrm{C}$ fosse melhor que $\mathrm{D}$. E, por sua vez, a quarta razão consegue explicar porque imaginamos uma quantidade muito grande de números de maneira inexata: porque uma quantidade muito grande de números nos é presumivelmente extraordinária, pois ordinariamente nós lidamos com quantidades numéricas pequenas ou médias.

Em contraste, nas comparações que envolvem trocas (tradeoffs) entre qualidade de bem-estar e quantidade de pessoas, erros pequenos nas quantidades imaginadas são bem mais comprometedores, como no caso da comparação proposta pela Conclusão Repugnante (GUSTAFSSON, no prelo). Por exemplo, suponha que a população $A$, de 10 bilhões de 
habitantes, tenha um bem-estar muito alto de 99 unidades, e a população B tenha 1 trilhão de habitantes com um bem-estar muito baixo de 1 unidade. Somando o bem-estar total das duas populações, seguindo um princípio de ordenação totalista, concluiríamos que a população $A$, que tem um valor total de 990 bilhões de unidades, é pior do que a população B, que tem um valor total de 1.000 bilhões de unidades. Contudo, se nós estivermos imaginando erroneamente a quantidade de 1.000 bilhões, referente à quantidade de pessoas em B, subestimando-a em apenas $2 \%$ de seu valor, imaginando-a como se ela tivesse 980 bilhões de habitantes, então a população A parecerá melhor do que a população B, pois 990 bilhões de unidades é maior do que 980 bilhões. Portanto, como não parece improvável que a margem de erro da quantidade imaginada seja maior ou igual a $2 \%$, tendo em vista que essa quantidade é extraordinariamente grande, essa intuição repugnante que nos impele a preferir a população A, ao invés da B, não é confiável.

Pode-se argumentar, porém, que se para termos uma intuição repugnante não for necessário que imaginemos uma quantidade numérica extraordinariamente grande, então nós podemos confiar nessa intuição. No que se segue, objetarei a duas maneiras (TEMKIN, 2012; PUMMER, 2013) de se argumentar assim, a favor da não-necessidade de imaginarmos quantidades numéricas extraordinariamente grandes para que tenhamos uma intuição repugnante e, portanto, a favor de podermos confiar nessa intuição.

\section{A maneira de Temkin}

As duas maneiras utilizam uma versão intrapessoal da Conclusão Repugnante, que chamarei de Picadas por Tortura, me baseando no exemplo From Torture to Mosquito Bites proposto por Temkin (2012, p. 135). Essa versão da Conclusão Repugnante pode ser descrita como se segue:

Picadas por Tortura. Para qualquer tortura que provoque uma dor excruciante por dois anos em uma pessoa, deve haver algum número grande o suficiente de anos, tal que, se as outras coisas forem iguais, é pior que uma 
pessoa sofra com a dor amena de uma picada de mosquito (com duração de 1 minuto), por esse número grande de anos, do que com a dor excruciante de uma tortura por dois anos. ${ }^{5}$

Novamente, agora em termos de uma única vida e de prejuízos, em vez de várias vidas e de benefícios (como na Conclusão Repugnante), parece que somos impelidos pela nossa intuição a acreditarmos que essa conclusão é claramente falsa. Acreditamos, prima facie, que sofrer com a dor excruciante de uma tortura por dois anos deve ser claramente pior do que sofrer com a dor amena de uma picada de mosquito, independentemente de quantos anos a dor da picada dure. No entanto, por uma axiologia totalista, somos levados a concluir que, se a soma total de dor da picada ao decorrer de muitos anos for maior que o total de dor da tortura por dois anos, é pior sofrer com a dor amena de uma picada de mosquito por uma quantidade suficientemente grande de anos.

É possível demonstrar essa conclusão a partir do que Temkin chama de "argumento de espectro" (spectrum argument), construindo um espectro de dores que varia da dor mais excruciante até a mais amena, diminuindo apenas um pouco a intensidade da dor anterior, e da menor duração de tempo até a maior, dobrando a quantidade de anos da dor anterior:

A1 Dor excruciante de uma tortura, por 2 anos;

A2 Dor apenas um pouco menos intensa que a anterior, por 4 anos;

A3 Dor apenas um pouco menos intensa que a anterior, por 8 anos;

${ }^{5}$ No exemplo original, além da tortura por dois anos, essa primeira vida também inclui a dor de 15 picadas de mosquito por mês durante toda a vida, que é uma condição de fundo constante em todas as alternativas de vida do espectro de dores proposto por Temkin. Assim, para ser mais preciso, a outra alternativa, de uma vida que sofreria com a dor de uma picada de mosquito, é na verdade de uma vida que sofrerá com a dor de 15 picadas por mês durante toda a vida mais uma, a que foi explicitada, durante uma quantidade suficientemente grande de anos. Por motivos de simplificação, deixei implícita essa constante de 15 picadas, justamente por ser constante em ambas as alternativas. Outra modificação que fiz: determinei uma duração para a dor de cada picada, a de 1 minuto (com base na versão de Pummer), já que Temkin não deixa explícito qual é a duração da dor de cada picada, apenas a quantidade de picadas por mês. Essa modificação, contudo, também não é relevante para a argumentação que se segue, apenas aproxima as duas maneiras de argumentar empregadas por Temkin e Pummer, poupando que eu faça futuras qualificações à versão de Pummer. 
A $n$ Dor amena de uma picada de mosquito, por uma quantidade de anos suficientemente grande

Ao compararmos alternativas adjacentes desse espectro, como A1 e A2, fica claro que, por uma axiologia total, a alternativa anterior é melhor que a posterior e, portanto, por paridade de comparação, também é claro que A $n-1$ é melhor do que An. Logo, se a relação "melhor que" for transitiva conclui-se que A1 é melhor que An.

Como já percebemos, essa conclusão é contraintuitiva. Intuitivamente, acreditamos que An é melhor que A1. No entanto, assim como no caso da Conclusão Repugnante, temos ao menos uma razão para sermos céticos quanto a essa intuição repugnante: ela exige que imaginemos uma quantidade muito grande de números. $\mathrm{O}$ que nos justifica a acreditar que exige? A diferença fenomenologicamente perceptível entre as intensidades destas dores extremas (de uma tortura e de uma picada). Assumindo que essa diferença é de fato bem grande, presume-se que para reduzir de pouco em pouco a intensidade da dor excruciante de uma tortura, até chegar na intensidade da dor amena de uma picada de mosquito, seriam necessárias muitas alternativas intermediárias entre A1 e An e, consequentemente, An seria uma alternativa com uma quantidade de anos muito grande, pois a cada pequena redução da intensidade da dor, de uma alternativa anterior para uma posterior, a quantidade de anos é dobrada.

Pode-se objetar, assim como Temkin (2012, p. 154-161), que não são necessárias muitas alternativas intermediárias para reduzir, de pouco em pouco, a intensidade da dor excruciante de uma tortura até a intensidade da dor amena de uma picada de mosquito, porque a diferença fenomenológica assumidamente grande entre essas dores extremas pode ser superada com poucas reduções de intensidade, tomando como evidência que o modo como

6 A relação "melhor que" é transitiva se, e somente se, dadas duas quaisquer três alternativas $\mathrm{A}, \mathrm{B}$ e $\mathrm{C}$, se A é melhor que B e B é melhor que $\mathrm{C}$, então A é melhor que $\mathrm{C}$. 
percebemos as dores é possivelmente ${ }^{7}$ análogo ao modo como percebemos as cores e as alturas. Assim, por esses modos serem possivelmente análogos, e por ser possível superar grandes diferenças fenomenológicas entre alturas ou cores extremas com poucas reduções de tamanho das alturas ou da temperatura das cores e, consequentemente, sem que o espectro de alturas ou de cores precise ter muitas alternativas, podemos inferir que é analogamente possível superar a diferença fenomenológica entre essas dores extremas com poucas reduções intermediárias na intensidade e na duração das dores, sem que o espectro de dores precise ter muitas alternativas (Ibid, p. 155-157).

Ênfase no "possivelmente", porque Temkin não se compromete com a atualidade desta analogia entre o modo como percebemos as dores e os modos como percebemos cores e alturas. Mesmo que esses modos não sejam de fato análogos, Temkin (Ibid, p. 157) defende que se for metafisicamente possível que eles sejam, então é possível que existam criaturas que sintam dores de tal forma que a extensão de suas dores extremas possa ser representada por um espectro de dores similar ao proposto por Temkin, mas com um número relativamente pequeno de alternativas (de sete alternativas, por exemplo, como no espectro de cores sugerido por Temkin). Assim, não é necessário que o espectro de dores proposto por Temkin tenha muitas alternativas para que uma diferença fenomenológica entre dores extremas, tão grande quanto a de uma tortura excruciante e a de uma picada de mosquito amena, seja superada com reduções pequenas de intensidade, o que implica que a alternativa da dor mais amena não precisa envolver uma quantidade muito grande de anos.

Portanto, a razão levantada pelo cético para desconfiarmos de certas intuições não se aplica a essa intuição repugnante que temos sobre a Picadas por Tortura. Se a dor de An não durar muitos anos, comparar A1 com An não exíge que imaginemos uma quantidade muito grande de números. Por

A possibilidade em questão, chamada por Temkin de possibilidade metafísica, também é por vezes chamada de possibilidade absoluta. De acordo com Plantinga (1974), que chama essa possibilidade de "possibilidade lógica em sentido amplo" (broadly logical possibility), ela é uma possibilidade mais restrita que a possibilidade lógica em sentido estrito, referente às restrições impostas pelas leis da lógica, porém menos restrita que a possibilidade física, referente às restrições impostas pelas leis da natureza do nosso mundo atual. 
exemplo, se o espectro de dores tiver sete alternativas, como o das cores, An terá uma duração de 128 anos, uma quantidade ainda assim extraordinária, apesar de não ser demasiadamente grande. Porém, se diminuirmos a duração de A1 para 1 ano, An terá uma duração de 64 anos, que é uma quantidade alegadamente ordinária, apesar de não ser tão comum alguém viver qualquer experiência positiva ou negativa por tanto tempo. Contudo, é possível diminuir a duração de $\mathrm{A} 1$ até que $\mathrm{A} n$ dure uma quantidade de tempo definitivamente ordinária.

Existem ao menos duas objeções possíveis a essa maneira de argumentar empregada por Temkin, contra desconfiarmos da intuição repugnante pela razão dela exigir que imaginemos uma quantidade muito grande de números. A primeira delas, sugerida por Norcross (1997, p. 151), é a de que mesmo que seja metafisicamente possível que esses modos de percepção sejam análogos (condição 1) e, consequentemente, que exista um espectro de dores ${ }^{8}$ com relativamente poucas alternativas, ainda assim essa possibilidade não é suficiente para que nós tenhamos uma intuição repugnante diante da comparação entre as alternativas extremas desse espectro: também é necessário que sua alternativa de dor mais amena seja claramente melhor do que sua alternativa de dor mais excruciante (condição 2) e, consequentemente, que a relação "melhor que" seja intransitiva e, portanto, que a transitividade da relação "melhor que" não seja necessariamente verdadeira. Logo, se acreditarmos que a transitividade da relação "melhor que" é necessariamente verdadeira, então é impossível existir um espectro de dores que tenha as condições 1 e 2 , pois a condição 2 implica na falsidade da transitividade da relação "melhor que".

Para ilustrar como a condição 1 não é suficiente para que tenhamos uma intuição repugnante, Norcross (Idem) propõe um espectro de dores de

${ }^{8}$ Daquí para frente, ocasionalmente, refiro-me à possibilidade da existência de um espectro de dores de maneira simplificada. Precisamente, na verdade, refiro-me à existência de um cenário possível em que a proposição "existem criaturas que tenham um espectro de dores relevantemente similar ao proposto pelo argumento de Temkin (que satisfaça as condições 1 e 2)" possa ser verificada como verdadeira ou falsa. Assim, ao decorrer da argumentação, refiro-me apenas à possibilidade de dicto dessas criaturas existirem, e não à possibilidade de re delas existirem 
alguma criatura metafisicamente possível que sinta dor de modo análogo a como percebemos as cores e as alturas. Nesse espectro, a pior dor dessa possível criatura, que tem dois anos de duração, é da mesma intensidade que a nossa dor de uma perna quebrada, e a sua dor mais amena é da mesma intensidade que a nossa dor de um tornozelo torcido. Claramente, esse espectro satisfaz a condição 1, pois a diferença fenomenologicamente perceptível entre as intensidades destas dores extremas, equivalentes a de uma perna quebrada e a de um tornozelo quebrado, é suficientemente pequena para que esse espectro não precise ter muitas alternativas intermediárias, que seriam necessárias para reduzir, de pouco em pouco, a dor de uma perna quebrada até chegar na intensidade da dor de um tornozelo quebrado, caso essa diferença fosse tão grande quanto a que existe entre a dor excruciante de uma tortura e a dor amena de uma picada de mosquito. No entanto, não está claro que 1 dia sofrendo com a dor da mesma intensidade que a de uma perna quebrada seja pior do que 128 dias sofrendo com a dor da mesma intensidade que a de um tornozelo quebrado assumindo que esse espectro tenha sete alternativas, e reduzindo a duração da dor equivalente a de uma perna quebrada para 1 dia, a fim de evitarmos qualquer inexatidão que poderia ocorrer ao imaginarmos quantidades extraordinárias de tempo. Logo, esse espectro de dores não satisfaz a condição 2 e, portanto, nós não temos uma intuição repugnante diante da comparação entre suas alternativas extremas, o que demonstra que a condição 1, referente à possibilidade dos modos de percepção das dores e das alturas/cores serem análogos, não é suficiente para que tenhamos uma intuição repugnante; também é necessário que ele satisfaça a condição 2.

Aceitar que é possível que exista um espectro de dores que satisfaça a condição 2, por sua vez, implica em aceitar que é possível que a transitividade da relação "melhor que" seja falsa. Entretanto, se acreditarmos que essa relação é transitiva pelo sentido que a relação "mais bom que" (more good than) possui (BROOME, 2004, p. 50-51), e assumirmos que essas relações são idênticas, então é impossível que essa relação não seja transitiva. Em outras palavras, essa relação ser transitiva é uma verdade necessária, pois não há mundo possível em que ela não seja transitiva, i.e., 
não há mundo possível em que a proposição "a relação 'melhor que' é transitiva" possa ser falsa; ela é necessariamente verdadeira. Portanto, não é possível que exista um espectro de dores que satisfaça as condições 1 e 2 necessárias para que tenhamos uma intuição repugnante confiável.

Suspeito que Temkin replicaria a essa primeira objeção, defendendo que é possível existir um espectro que satisfaça a condição 2 e, não obstante, a transitividade da relação "melhor que" não seja falsa, porque na verdade ela apenas não se aplica a essa relação, ou seja, ela não pode ser verdadeira ou falsa (TEMKIN, 2012, p. 163-170). Para compreender esta possível defesa, é crucial entender que, ao se perguntar qual das alternativas extremas do espectro é melhor, Temkin não está se referindo à relação "melhor que" que seria idêntica à relação "menos mau que", mas a uma outra relação "melhor que" com um sentido mais abrangente que essa, composta por duas relações "melhor que" particulares que, por sua vez, têm o mesmo sentido que a relação "menos mau que" - uma que compara e ordena alternativas com base em suas somas totais de mau, e outra que as compara e ordena com base na distribuição da quantidade de mau pelo seu tempo de duração. Logo, pode ser que a alternativa de dor mais amena desse espectro possível seja, nesse sentido mais abrangente, melhor do que a alternativa de dor mais excruciante e, mesmo assim, essa relação "melhor que" não ser intransitiva (pela transitividade ser falsa), mas sim não-transitiva (pela transitividade não se aplicar). As relações "melhor que" particulares, por sua vez, podem ser necessariamente verdadeiras, pelo sentido que elas possuem (que é o mesmo sentido da relação "menos mau que", que é trivialmente transitiva), mas a relação "melhor que" que as abrange ser não-transitiva e, portanto, a condição 2 pode ser satisfeita.

Vamos assumir, por uma questão de escopo deste artigo, que o argumento de espectro de Temkin realmente não está comprometido com a intransitividade da relação "melhor que". Segue-se, então, que um espectro de dores que satisfaça as condições 1 e 2 não é, ao menos a priori, impossível. Assim, Temkin conseguiria se livrar da primeira objeção. No entanto, ele ainda teria que lidar com esta segunda objeção: apesar desse espectro de dores não ser a priori e, consequentemente, aparentemente 
impossível, nós não podemos garantir que ele seja aparentemente possível. Colocada de outro modo; para justificar esta possibilidade, garantindo credibilidade a nossa capacidade de conhecê-la, Temkin precisaria mostrar de maneira a priori não apenas que o seu espectro de dores não é aparentemente impossível, mas também que ele é aparentemente possível. ${ }^{9}$

Epistemologicamente, de forma geral, toda e qualquer maneira $a$ priori de justificar nossas crenças modais exige imaginarmos um cenário ou mundo possível em que esse espectro pareça existir. De forma específica, seguindo a maneira proposta pela teoria da "concebibilidade" (conceivability) de Yablo (1993, p. 29-30), para sabermos se é aparentemente possível que esse espectro exista temos que conseguir conceber, pela nossa imaginação, um cenário coerente com um mundo possível em que a proposição $p$, "um espectro de dores que tenha as condições 1 e 2 existe", possa ser verificada como verdadeira ou falsa e, se for verdadeira, será aparentemente possível. Por exemplo, para saber se é aparentemente possível que este artigo nunca tivesse sido publicado, temos que conseguir imaginar um cenário, coerente com um mundo possível, em que a proposição $q$, "este artigo nunca foi publicado", possa ser verificada como verdadeira ou falsa; se for verdadeira, então ela é aparentemente possível.

Consigo conceber ao mènos um cenário, coerente com um mundo possível, no qual $q$ é verdadeira: o artigo foi submetido em uma revista periódica, mas teve dois pareceres negativos e, consequentemente, foi rejeitado (o que me desmotivou a submetê-lo novamente). Logo, $q$ é aparentemente possível. Todavia, creio que só podemos confiar nesta aparente possibilidade na medida em que esse cenário é suficientemente detalhado, a fim de que as condições de possibilidade que permitem que essa proposição seja verdadeira ou falsa fiquem explicitadas, para que a proposição $q$ seja passível de verificação. No entanto, seguindo o ceticismo

${ }^{9}$ Pode existir quem demande, mais fortemente, que Temkin mostre não apenas que esse espectro é aparentemente possível, mas também que ele seja de fato possível. Como eu não acredito que alguém consiga mostrar, de maneira a priori, que ele seja de fato possível, me contento com a demanda mais fraca, a de mostrar que ele é aparentemente possível 
modal moderado de Inwagen (1998), desconfio da nossa capacidade imaginativa de conceber um cenário possível que seja suficientemente detalhado para verificar se a proposição $p$ é verdadeira ou falsa.

Veja, não é suficiente que imaginemos um cenário em que uma criatura que sente as dores de um modo diferente do nosso exista, tal que elas possam ser representadas por um espectro de dores que satisfaz as condições 1 e 2: também é necessário conceber como esse modo de sentir dor pode ser representado por um espectro que satisfaz essas condições 1 e 2 ou, no final das contas, como seria sentir dor desse modo, nesse cenário. Da mesma forma, para conceber a possibilidade de $q$ tive que imaginar como este artigo nunca veio a ser publicado, não bastando apenas imaginar que ele nunca foi publicado. Tecnicamente falando, ainda seguindo Yablo (1993, p. 27), para conceber $p$ como aparentemente possível temos que imaginar não só as condições de possibilidade proposicionais de $p$ (que dizem respeito às propriedades expressas pela proposição que tornam o seu objeto passível de ser referido), mas também as suas condições de possibilidade objetais (que dizem respeito ao objeto referido pela proposição que a torna passível de ser verificada como verdadeira ou falsa).

A razão desta minha desconfiança, sobre conseguirmos conceber um cenário possível suficientemente detalhado para verificar se a proposição $p$ é verdadeira, é essencialmente a mesma por que desconfio de intuições que exigem imaginarmos quantidades numéricas muito grandes: para imaginarmos as condições de possibilidade objetais de $p$ nós teríamos que imaginar um objeto extraordinário, a saber, uma criatura que possua um modo de perceber suas dores tal que elas possam ser representadas por um espectro que satisfaça as condições 1 e 2 , pois se assumirmos que nós não percebemos as dores desse modo ${ }^{10}$, então ele é distinto do nosso e, portanto, incomum. De acordo com Inwagen (1998, p. 69-70), nós até podemos conhecer algumas proposições modais: as que se referem a objetos

${ }^{10}$ Creio que seja seguro assumir que nós não percebemos, tendo em vista que a diferença fenomenologicamente perceptível entre nossas dores extremas, entre a dor excruciante de uma tortura e a dor amena de uma picada de mosquito, é grande demais para que possamos representar a extensão de nossas dores em um espectro que satisfaça ambas as condições. 
ordinários — como é o caso da proposição $q$ — ou que se referem a objetos que podem ser verificados como verdadeiros ou falsos dedutivamente, por raciocínio lógico ou matemático, a partir do sentido que as propriedades desses objetos possuem. No entanto, dada a nossa incapacidade de imaginar objetos extraordinários com um grau de detalhe suficiente para conceber as suas condições de possibilidade objetais, nós não podemos conhecer proposições modais como a proposição $p$, que se referem a objetos extraordinários.

Para ilustrar essa incapacidade imaginativa, Inwagen (Idem) propốe uma analogia entre nossas capacidades de adquirir conhecimentos modais e nossas capacidades de adquirir conhecimentos perceptuais a partir do que podemos enxergar a olho nu. Por exemplo, assim como por meio da visão nós conseguimos saber se uma árvore está a mais ou menos 10 metros de distância de nós, também conseguimos saber se eu poderia ser uma pessoa que sabe Álgebra, e assim como nós não conseguimos por meio da visão saber se o Sol está a quase 150 mil quilômetros de distância da Terra, também não conseguimos saber se é possível existir um ser omnisciente. Os dois conhecimentos que nós podemos ter, sobre se a distância da árvore vista a olho nu é de mais ou menos 10 metros e se eu poderia saber Álgebra, são conhecimentos sobre objetos com propriedades ordinárias — uma árvore a uma distância ordinária e uma pessoa que aprendeu um conteúdo ordinário da Matemática - por oposição, os dois conhecimentos que nós não podemos ter, sobre se a distância do Sol visto a olho nu está a quase 150 mil quilômetros de distância e se é possível existir um ser omnisciente, são conhecimentos sobre objetos com propriedades extraordinárias — uma estrela a uma distância extraordinária, em relação às distâncias que ordinariamente percebemos a olho nu, e um ser com uma propriedade definitivamente extraordinária: a de saber tudo que é cognoscível. Em suma, a intuiçáo ilustrada por esse exemplo é a de que assim como nós não somos capazes de enxergar objetos irrestritamente, também não somos capazes de imaginar objetos irrestritamente.

Essa intuição é justificada quando tentamos conceber um cenário, coerente com um mundo possível, em que algum desses objetos 
extraordinários pareça existir, mas não conseguimos imaginar as condições de possibilidade objetais desse cenário. Por exemplo, para conseguirmos saber se é aparentemente possível que exista um ser omnisciente, pela abordagem concebibilista de Yablo, teríamos que conceber um cenário possível em que a proposição $r$, "existe um ser omnisciente", possa ser verificada como verdadeira. Novamente, para conceber esse cenário, não basta imaginar proposicionalmente que existe um ser que tem a propriedade de ser omnisciente, também é preciso imaginar objetualmente quais as condições de possibilidade que permitem que esse ser exista. Obviamente, como ponto de partida, temos que uma das condições é a de que esse ser tenha uma capacidade cognitiva distinta da nossa (e, presumivelmente, melhor que a nossa), uma vez que não somos omniscientes. Porém, o quão diferente ou melhor ela teria que ser para que ele seja omnisciente? Quais outras propriedades o mundo possível e o próprio ser teriam que ter para que ele possa existir nesse cenário? Nada disso parece claro.

Seguindo Inwagen (1998, p. 79-81), portanto, devemos desconfiar de quem acredita ter imaginado objetualmente um cenário, coerente com um mundo possível, em que $r$ seja verdadeira. Tendo em vista nossa incapacidade imaginativa de conceber estes cenários possíveis, que são necessários para verificar essas proposições que se referem a objetos extraordinários - por não conseguirmos imaginá-los de maneira suficientemente detalhada para termos clareza de quais são as suas condições de possibilidade - , parece que estamos justificados a desconfiar que alguém possa verificar que $r$ seja verdadeira. Pela mesma razão, também deyemos desconfiar de quem acredita poder imaginar objetualmente um cenário, coerente com um mundo possível, em que $p$ seja verdadeira. Assim, devemos ser céticos sobre se é aparentemente possível que exista uma criatura que sinta suas dores de modo distinto do nosso, tal que elas possam ser representadas por um espectro que tenha as condições 1 e 2 .

Quem acredita no contrário, que não devemos ser céticos, tem que poder responder claramente as seguintes questões: o quão diferente esse modo de sentir dores deve ser para que elas possam ser representadas por esse espectro que satisfaz as condições 1 e 2? Quais outras propriedades o 
mundo possível e a própria criatura teriam que ter para que ela possa existir nesse cenário? Aqui também, infelizmente, não são claras as respostas. Logo, Temkin não conseguirá mostrar que seu espectro de dores é aparentemente possível e, consequentemente, que nós podemos ter uma intuição repugnante que não exija imaginarmos uma quantidade extraordinária de números.

\section{A maneira de Pummer}

Talvez esse argumento, a favor de nós podermos ter uma intuição repugnante confiável sobre a Picadas por Tortura - porque essa intuição não exige que imaginemos uma quantidade extraordinária de números ainda seja decisivamente sólido, mesmo que não o seja pelo motivo de que é metafisicamente possível existir um espectro de dores que satisfaça as condições 1 e 2 (como sugere a argumentação de Temkin), mas sim porque, como sugere Pummer (2013) em seu artigo Intuitions about large numbers, nós podemos extrapolar a confiança sobre a comparação da Picadas por Tortura $^{11}$, que exige imaginarmos uma quantidade extraordinária de tempo, a partir de comparações que exigem imaginarmos quantidades ordinárias de tempo e que, portanto, são aparentemente confiáveis.

A argumentação de Pummer consiste em dois argumentos. No primeiro deles, Pummer (Ibidem, p. 40) de início concede a nós céticos que, dado que os seres humanos são limitados na atualidade, não é possível imaginarmos, de maneira confiável, quantidades muito grandes de números. Todavia, num sentido menos restrito de possibilidade, Pummer sugere que a seguinte proposição s é verdadeira: nós estamos justificados a acreditar que se fosse possível para nós imaginar, de maneira relevante (e, portanto, confiável), grandes quantidades numéricas, então nós teríamos uma intuição

11 Na verdade, Pummer utiliza uma versão similar a Picadas por Tortura chamada Hangnails for Torture. A única diferença é que, na versão de Pummer, a dor mais amena é de uma "unha encravada" (hangnail) com duração de 1 minuto. Para simplificar, como acredito que essa diferença nas versões seja irrelevante, escolhi manter a versão de Temkin para expor o argumento de Pummer 
repugnante confiável de que a Picadas por Tortura é falsa. E portanto, assumindo a verdade de outra proposição condicional $t$ (que é claramente verdadeira) - a de que, se $s$ for verdadeira, então nós temos uma razão para acreditar que a Picadas por Tortura é falsa — podemos concluir, seguindo Pummer, que nós temos uma razão para acreditar que a Picadas por Tortura é falsa.

Pelo segundo argumento, de acordo com Pummer (lbidem, p. 41), podemos argumentar a favor da verdade de $\mathrm{s}$ levando em conta a seguinte comparação variável:

Comparação Variável. Dois anos sofrendo com a dor de uma tortura excruciante é, se as outras coisas forem iguais, pior do que $\mathrm{X}$ anos sofrendo com dores de picadas de mosquito amenas (cada uma com a duração de um minuto) ${ }^{12}$

Considerando essa comparação, se 0 antecedente da condicional de $s$ for verdadeiro - i.e., se fossemos capazes de imaginar relevantemente qualquer quantidade de anos de picadas de mosquito - então teríamos duas hipóteses excludentes sobre a verdade dessa comparação variável: a hipótese $h 1$, de que nós teríamos a intuição de que não há algum número de dores de picadas de mosquito tal que seja pior sofrer com elas do que com a dor de uma tortura excruciante por dois anos; e a hipótese $h 2$, de que nós teríamos a intuição de que há algum número de dores de picadas de mosquito tal que seja pior sofrer com elas do que com a dor de uma tortura excruciante por dois anos. Pummer (Ibidem, p. 42) defende que nós podemos justificar a crença de que $h 1$ é mais plausível que $h 2$, e que, portanto, $s$ é verdadeira, a partir do seguinte "Argumento da Extrapolação" (Extrapolation Argument):

${ }^{12}$ Vale notar que, diferente da comparação da' Picadas por Tortura, a Comparação Variável não está formulada em função de um único indivíduo sofrendo com a dor de uma picada de mosquito por mês durante vários anos, mas sim em função de anos de dores de picadas de mosquito. No entanto, é fácil ver que a comparação da Picadas por Tortura pode ser trivialmente reformulada em função de anos de dores de picadas de mosquito: e.g., a dor de uma picada de mosquito por mês durante 100 anos é equivalente a 100 anos de dores de picadas de mosquito, i.e., equivalente a 120 dores 
1. Se $h 2$ fosse verdadeira, e, portanto, $h 1$ fosse falsa, então quanto maior imaginássemos a quantidade $\mathrm{X}$ de anos, menos confiantes nós ficaríamos sobre a verdade da Comparação Variável.

2. Nós não ficamos menos confiantes sobre a verdade da Comparação Variável à medida que imaginamos $\mathrm{X}$ como sendo maior do que era. $\therefore h 1$ é verdadeira e $h 2$ é falsa.

Para ilustrar esse argumento, podemos dobrar o valor de $\mathrm{X}$ progressivamente, seguindo Pummer (Ibidem, p. 41), começando com 4 anos. Para evitarmos ao máximo qualquer inexatidão, dobraremos $X$ até chegarmos a 64 anos de dores de picadas de mosquito, pois 128 anos é uma quantidade de tempo extraordinária para a vasta maioria dos humanos ${ }^{13}$. Temos, então, 5 comparações intuitivamente verdadeiras em que é pior sofrer com a dor de uma tortura excruciante por 2 anos do que com as dores de picadas de mosquito por $\mathrm{X}$ anos $(4,8,16,32$ e 64 anos, respectivamente) e que, por não envolverem quantidades extraordinárias de tempo, são aparentemente confiáveis. Pela premissa 1 , se $h 2$ fosse verdadeira, i.e., se houvesse algum número de dores de picadas de mosquito tal que fosse pior sofrer com elas do que com 2 anos da dor de uma tortura excruciante, então nós teríamos menos confiançà na verdade da primeira comparação, de que é pior sofrer com 2 anos de tortura do que com 4 anos de picadas, do que teríamos na verdade da segunda comparação, de que é pior sofrer com 2 anos de tortura do que com 8 anos de picadas (assim sucessiva e progressivamente, até que $X$ seja igual a 64 anos). Em consonância com a premissa 2, parece que muitos de nós, inclusive eu, não percebemos uma perda progressiva na confiança que temos sobre essas comparações serem verdadeiras. Portanto, dado que as dores e os anos das comparações foram

13 Mesmo que a inexatidão na quantidade imaginada não comprometa totalmente a comparação entre 2 anos de tortura excruciante e 128 anos de picadas de mosquito amenas, ainda assim parece plausível pensar que essa inexatidão possa comprometer um pouco a comparação, e se a inexatidão consistir numa subestimação do valor da dor de 128 anos de picadas de mosquito amenas, então parece plausível assumir que poderíamos perder alguma confiança na verdade da Comparação Variável caso não houvesse tal subestimação (se pudéssemos imaginar quantidades extraordinárias de maneira exata). 
diminuídas e aumentados continuamente, $h 2$ deve ser falsa e $h 1$ verdadeira: não existe algum número de dores amenas de picadas de mosquito tal que seja pior sofrer com elas do que com a dor excruciante de uma tortura por dois anos. Do contrário, nós teríamos que perceber uma redução contínua da nossa confiança, pois os fatores relevantes - a dor e o tempo - variam de maneira contínua neste espectro de dores de 5 alternativas.

Assim posto, envolvendo apenas 5 quantidades ordinárias de tempo, esse argumento é relativamente fraco, como o próprio Pummer (Ibidem, p. 42 , nota 5) parece admitir. O argumento fica mais forte na medida em que incluímos mais comparações, garantindo mais credibilidade à extrapolação. No entanto, como incluir mais comparações sem que elas envolvam quantidades extraordinárias de tempo? Pummer (Ibidem, p. 41) sugere que podemos imaginá-las como se elas fossem quantidades ordinárias de pessoas sofrendo com as dores de picadas de mosquito por 1 ano. Por exemplo, podemos imaginar relevantemente o equivalente a 128 anos de dores de picadas de mosquito (sofridas por uma única pessoa) ao imaginarmos 128 pessoas sofrendo com dores de picadas de mosquito por 1 ano. De fato, grande parte de nós já esteve em lugares ocupados por centenas de pessoas (e.g., no auditório lotado em uma conferência ou na praça de alimentação de um shopping). Logo, essa quantidade de pessoas não parece ser extraordinária. Pummer (Ibidem, p. 42) parece sugerir ainda mais: que pelo menos alguns indivíduos (e.g., torcedores de futebol que assistem jogos em estádios ocupados por milhares de espectadores) podem imaginar relevantemente milhares de pessoas sofrendo com dores de picadas de mosquito e, por equivalência, uma única pessoa sofrendo com dores de picadas de mosquito por milhares de anos.

Explicitada essa maneira de argumentar empregada por Pummer, passo a apresentar minhas objeções a ela. Primeiro, sobre a plausibilidade do Argumento da Extrapolação em suas versões relativamente mais fortes, suspeito que imaginar dores de picadas de mosquito sofridas por várias pessoas por 1 ano não seja equivalente a imaginar dores de picadas de mosquito sofridas por uma única pessoa por vários anos, mesmo que estes dois agregados de dores sejam, no total, numericamente iguais. Talvez sejam 
equivalentes para seres que tenham capacidades imaginativas ideais, mas acredito que a maioria de nós, que possuímos uma capacidade imaginativa não-ideal, imagina esses dois agregados de dores, sofridas por várias pessoas e sofridas por uma única pessoa, com alguma dose de enviesamento, dando um peso menor às dores sofridas por várias pessoas por 1 ano do que às dores sofridas por uma única pessoa por vários anos, embora elas sejam numericamente equivalentes. Logo, pode ser que nós não perdemos confiança na verdade da Comparação Variável conforme aumentamos X, imaginando $\mathrm{X}$ anos de dores em uma única pessoa como se fosse o mesmo que imaginar o equivalente numérico de $\mathrm{X}$ pessoas sofrendo com essas dores por 1 ano, porque subestimamos o valor dessas dores, ao imaginá-las como se estivessem distribuídas entre várias pessoas, justamente por estarem distribuídas/dispersadas.

Outro motivo que pode explicar porque não perdemos essa confiança é que, apesar de centenas ou milhares de pessoas serem de fato quantidades ordinárias, a maioria de nós imagina essas quantidades de maneira inexata, pois não estamos devidamente familiarizados com espaços ocupados por essas quantidades de pessoas. Para exemplificar, vamos considerar centenas de pessoas numa praça de alimentação. Se frequentarmos muito essa praça, e soubermos quantas pessoas ocupam o espaço quando estamos nele (imagine que conhecemos o chefe de segurança do local e temos acesso aos dados da vigilância), podemos aperfeiçoar nossa intuição sobre a quantidade de pessoas ocupando essa praça, a ponto de conseguirmos saber com uma confiabilidade razoável (sem olhar os dados da vigilância) que num dado momento, em que estamos comendo na praça, cerca de 200 pessoas estão ocupando o espaço, e não 100. No entanto, não parece igualmente confiável que saibamos que, num outro momento, cerca de 220 pessoas ocupavam o espaço, e não 180. Parece menos confiável ainda que saibamos, num outro momento e num outro espaço (que nós frequentamos pouco, e.g., um bar universitário que fomos apenas uma vez), cerca de 220 pessoas ocupavam o espaço, e não 180. Logo, sem condições de imaginação objetais referentes a um espaço que nos seja relativamente familiar, parece provável que nós imaginaremos essas quantidades de 
pessoas de maneira inexata e talvez subestimada; consequentemente, podemos subestimar o valor das dores sofridas por essas pessoas e, portanto, confiarmos mais do que deveríamos nas comparações entre a dor excruciante de uma tortura por 2 anos e as dores de picadas de mosquito por $\mathrm{X}$ anos.

Se não subestimássemos o valor das dores de picadas de mosquito por $\mathrm{X}$ anos, por imaginá-las distribuídas em $\mathrm{X}$ pessoas por 1 ano - tanto porque imaginamos essas dores de maneira enviesada quando as consideramos como se fossem dores distribuídas entre várias pessoas, quanto porque imaginamos as quantidades de pessoas sofrendo essas dores de maneira relativamente inexata - então parece plausível pensar que talvez nós perderíamos alguma confiança na verdade da Comparação Variável, na medida em que dobramos a duração $\mathrm{X}$ dessas dores, o que demonstraria que $h 2$ é verdadeira e $h 1$ é falsa. Acredito que, dada esta possibilidade de que a premissa 1 seja falsa, devemos desconfiar da solidez do Argumento da Extrapolação em suas versões relativamente mais fortes, que envolvem quantidades de tempo extraordinárias.

Em sua versão mais fraca, entretanto, o Argumento da Extrapolação parece sólido e fornece alguma justificativa à verdade de $s$. Contudo, defendo que essa justificativa é minada quando analisamos o antecedente da condicional expressa por $s$ e, mais precisamente, o sentido de possibilidade que ela expressa. Por um lado, se essa proposição condicional estiver comprometida com um sentido de possibilidade metafísica - i.e., se ela expressar que nós estaríamos justificados a acreditar que, caso fosse metafisicamente possível imaginarmos quantidades numéricas muito grandes, segue-se que nós teríamos uma intuição repugnante confiável de que a Picadas por Tortura é falsa — então eu defenderia, seguindo novamente o ceticismo modal de Inwagen, que nós não podemos decidir se essa proposição é verdadeira ou falsa, uma vez que não conseguiríamos decidir se o antecedente da condicional é verdadeiro ou falso. Afinal, quais são as condições de possibilidade objetais que tornam esse antecedente passível de verificação? Quão melhor nossa capacidade de imaginar quantidades seria neste cenário? Que outras propriedades nós mesmos e esse 
cenário, coerente com um mundo possível, deveriam ter para que essa capacidade seja aparentemente possível? Acredito que não temos respostas suficientemente relevantes para essas perguntas.

Por outro lado, se essa proposição estiver comprometida com uma possibilidade lógica em sentido estrito ${ }^{14}$, referente apenas às restrições impostas pelas leis da lógica, então defendo que a proposição é falsa mesmo que o antecedente possa ser verificado, de maneira a priori, como aparentemente verdadeiro. Não estamos justificados a acreditar que o consequente é verdadeiro, i.e., que nós teríamos uma intuição repugnante confiável sobre a falsidade da Picadas por Tortura, apenas porque é logicamente possível (em sentido estrito) que nós fôssemos capazes de imaginar quantidades extraordinárias de tempo: também é necessário que seja metafisicamente possível que nós fôssemos capazes de imaginar quantidades extraordinárias de tempo, pois se $\mathrm{o}$ antecedente fosse metafisicamente impossível, mas logicamente possível, então o consequente seria falso.

Portanto, essa proposição condicional $s$ só pode ser verdadeira se estiver comprometida, no que se refere ao conteúdo proposicional do seu antecedente, com um sentido metafísico de possibilidade. Assim, posto que essa possibilidade não é trivialmente verdadeira, Pummer teria que mostrar que esse antecedente é verdadeiro, i.e., que é possível que fôssemos capazes de imaginar relevantemente quantidades numéricas extraordinárias, antes de argumentar (via Argumento da Extrapolação) a favor da hipótese $h 1$ de que, caso fôssemos capazes, nós teríamos a intuição de que não há algum número de dores de picadas de mosquito tal que seja pior sofrer com elas do que com a dor de uma tortura excruciante por 2 anos. Como já vimos, no entanto, acredito que não somos capazes de mostrar que essa possibilidade metafísica é aparentemente verdadeira.

Pummer (Ibidem, p. 40, nota 4) não deixa explicitamente claro se a possibilidade em questão é uma possibilidade lógica em sentido amplo e, portanto, metafísica, ou uma possibilidade lógica em sentido estrito. Contudo, como ele diz estar investigando o que ocorreria em mundos logicamente possíveis em que nossas capacidades imaginativas fossem melhoradas, creio que ele esteja se referindo à possibilidade lógica em sentido amplo, e não à possibilidade lógica em sentido estrito 


\section{Conclusão}

Após investigar esse argumento a favor de nós podermos confiar na intuição repugnante (tanto pela maneira de Temkin, quanto pela de Pummer) - porque ela não exige que imaginemos uma quantidade extraordinariamente grande de números - concluo que nós devemos manter nossa desconfiança sobre a verdade expressa pela intuição repugnante, uma vez que a solidez de ambas as maneiras depende, em última instância, da possibilidade metafísica de entes extraordinários existirem, i.e., de um espectro de dores que satisfaça as condições 1 e 2 (na maneira de Temkin) e de uma capacidade de imaginar idealmente quantidades numéricas muito grandes (na maneira de Pummer), mas não conseguimos mostrar que esses entes são aparentemente possíveis, ou melhor, que as proposições modais, que afirmam a possibilidade metafísica desses entes existirem, são aparentemente verdadeiras.

\section{Referências}

ARRHENIUS, Gustaf. Future generations: A challenge for moral theory. 2000. Tese de Doutorado. Acta Universitatis Upsaliensis.

ARRHENIUS, Gustaf, RYBERG, Jesper; TÄNNSJÖ, Torbjörn. The repugnant conclusion. 2006.

BROOME, John. Weighing Lives. Oxford University Press, 2006.

COWIE, Christopher. The repugnant conclusion: A philosophical inquiry. Routledge, 2019. https://doi.org/10.4324/9780429468117

GREAVES, Hilary. Population axiology. Philosophy Compass, v. 12, n. 11, p. e12442, 2017. https://doi.org/10.1111/phc3.12442 
GUSTAFSSON, Johan E. Our intuitive grasp of the repugnant conclusion. In: Population Ethics: The Challenge of Future Generations. Oxford University Press, No Prelo.

HUEMER, Michael. In defence of repugnance. Mind, v. 117, n. 468, p. 899-933, 2008. https://doi.org/10.1093/mind/fzn079

NG, Yew-Kwang. What Should We Do About Future Generations?: Impossibility of Parfit's Theory X. Economics \& Philosophy, v. 5, n. 2, p. 235-253, 1989. https://doi.org/10.1017/S0266267100002406

NORCROSS, Alastair. Comparing harms: headaches and human lives. Philosophy \& Public Affairs, v. 26, n. 2, p. 135-167, 1997. https://doi.org/10.1111/j.1088-4963.1997.tb00079.x

PARFIT, Derek. Reasons and persons. Oxford University Press, 1984.

PLANTINGA, Alvin. The nature of necessity. Oxford University Press on Demand,1974.

PUMMER, Theron. Intuitions about large number cases. Analysis, v. 73, n. 1, p. 37-46, 2013. https://doi.org/10.1093/analys/ans134

TÄNNSJÖ, Torbjörn. Why we ought to accept the repugnant conclusion. Utilitas, v. 14, n. 3, p. 339-359, 2002. https://doi.org/10.1017/S0953820800003642

TEMKIN, Larry S. Rethinking the good: Moral ideals and the nature of practical reasoning. Oxford University Press, 2012. https://doi.org/10.1093/acprof:oso/9780199759446.001.0001 
VAN INWAGEN, Peter. Modal epistemology. Philosophical Studies, p. 67-84, 1998.

YABLO, Stephen. Is conceivability a guide to possibility?. Philosophy and Phenomenological Research, v. 53, n. 1, p. 1-42, 1993. https://doi.org/10.2307/2108052

ZUBER, Stéphane et al. What should we agree on about the repugnant conclusion?. Utilitas, p. 1-5, 2021.

Data de registro: 31/08/2021

Data de aceite: $25 / 11 / 2021$ 